\title{
Communicating Virtually: The Case of Blogging in Professional Environments
}

\author{
Begoña Montero-Fleta, Member, IACSIT, and Carmen Pérez-Sabater
}

\begin{abstract}
The literacy demands of work are changing in the face of current global communication networks. This paper focuses on the methodology adopted in a university degree to practise workplace interaction in English, the lingua franca in professional settings. In the present study, the authors have observed the effect of the incorporation of computer-mediated communication combined with simulation-type methodology to improve students' workplace writing and motivation. Students worked in groups and "blogged" pseudo-professionally with other groups. The analysis of the results shows high motivation on the part of the students. The "writing for a purpose" has permitted more and better language, which indicates that blogs are a potential tool for the development of linguistic skills.
\end{abstract}

Index Terms - Blogging, simulation, second language writing, virtual communication. workplace language.

\section{INTRODUCTION}

Higher education programs must integrate methodologies in the classroom to meet the demands for literacy and communicative skills of todays' workforce. Communication technologies have improved at lightning speed and today's new contexts of work have led to daily virtual exchange of information in which English is the Lingua Franca used. In this context, new programs such as CoMoViWo (Communication in Mobile and Virtual Work) are being developed to generate methods and learning modules for teaching communication and the language skills needed in virtual, intercultural working environments.

Likewise, the incorporation of asynchronous computer-mediated communication in the classroom is currently in need of research. This paper puts into practice an asynchronous computer-mediated communication tool combined with simulation-type methodology to improve the workplace writing skills and motivation of university-level students' of English as a foreign language. The use of blogging, combined with a simulation-type active methodology, help students cultivate those general abilities that facilitate life-long learning.

Between simulation and gaming and the use of a language, both native and second or foreign, there are many points in common. The two cases involve models, representations, realities and negotiated meanings. Simulation and gaming allows participants to intervene and interpret the world,

Manuscript received October 10, 2014; revised February 4, 2015. This work was supported in part by CoMoViWo, a Project financed by the Education, Audiovisual and Culture Executive Agency (EACEA) of the European Union within the Erasmus + Programme.

The authors are with School of Informatics, Universitat Politècnica de València, Spain (e-mail: bmontero@idm.upv.es). generating language models in agreement with the content and the context. In the untiring search for effective teaching resources, simulation and gaming comes forth as a flexible, open instrument with many possibilities for learners to interact [1]. From the 1970s, ever since the learning emphasis has been placed on communication skills, simulation and gaming has been used in language learning situations. Nowadays, the profound modification of university educational models in Europe has led to new methodologies aiming at students' life-long learning for both personal and professional purposes. Simulation of "real-life" situations has become one of the techniques used in higher education to prepare students to communicate effectively in the international labor market.

In parallel, technological innovations have also had an important effect on current learning styles: computer-mediated communication today is used as a bridge for the development of written and spoken skills for learners [2]; its effectiveness, though, is heavily dependent on how it is used [3]. However, the use of technology alone does not improve achievement and motivation among pupils; it also necessitates a methodology which is pedagogically sound and leads to effective learning, "real life" communication and projection into the professional world. Among these methodologies are those techniques related to simulation and gaming [1].

\section{Simulating Professional EXCHANGES IN ENGLISH THROUGH BLOGGING}

At the moment, blogging is one of the tools used by professionals to maintain contact with their peers and to stay up-to-date in their professions [4]. In general, blogging is useful for dissemination of information, for communication and for reflection. In the classroom, along with these benefits, blogs can be suitable in the classroom for providing teachers and learners with multiple possibilities to enhance their daily practice due to their multimedia features, interactivity and realism. This environment lends itself to simulation activities. In language learning, blogs can be used as tools to develop writing skills and, although they should not replace face-to-face interaction, they may provide a practice environment where students can think, reflect, and create language slowly for a real-life audience [5].

The major benefits of blogging in the language classroom have been reported as "the choice of more appropriate language on the part of the learners, the addition of new perspectives to the learners' thoughts, and the motivational aspect of realizing that one's voice echoes in distant parts of the globe and is heard by others" [6]. Montero-Fleta and 
Pérez-Sabater [7] and Pelletieri [8] emphasize its positive effects on improving grammar proficiency and fluency. Sun's findings [9] suggest that blogs can constitute a dynamic forum that fosters extensive practice, motivation for learning, authorship, and development of learning strategies. The added value of using blogs means that students produce contents that are instantly accessible on the web, which can potentially attract comments from other users, whether they are classmates or anonymous bloggers [10].

As for motivation, it has been reported as the most critical factor for success in language teaching through computers [11]. The study of motivation in the language classroom reached an exciting turning point in the 1990s, resulting in 'motivational renaissance'. Motivation has become central to a number of theories of L2 acquisition (for a recent overview see Ushioda, [12]), and has been defined as the activation or goal-oriented behaviour, i.e., what moves a person to make certain choices, to engage in action, and to persist in action [12]. An activity in the classroom which has shown itself to rank high as a "motivator" is precisely simulation [13], [14]. Motivation is also a crucial factor in blog interaction for the workplace [4].

The present research aims at studying the improvement of writing fluency and form correctness of university students of English participating in professional blogs and the motivation raised by this innovative activity. Participation was a compulsory task with weighting appropriate to its importance (50\% of course assessment). This participation entailed the students' involvement in the following activities: visiting blogs and posting their own entries, reflecting on the blog entries sent by their peers, reflecting on the comments received and writing a self-reflection portfolio on the experience.

\section{HYPOTHESIS}

Our research aims at confirming the following hypotheses:

1) Writing skills and fluency are more likely to show a higher improvement by actively simulating professional participation in blogs than leading traditional teaching in the language classroom.

2) Motivation increases through these simulation activities.

\section{MATERIALS AND METHODS}

\section{A. Subjects}

It has been scholarly researched that blogging is an important issue for librarianship where information search and retrieval skills are integral to the job [15], [16]. This experiment was run with 32 Spanish students of English in a university degree of Library and Information Management over the course of a semester. The average age of the students was 23.6 and their level of English was supposed to be intermediate (B1 on the Common European Framework of Reference for Languages) but there was a wide range of language proficiency levels. They were experienced users of new technologies. Classes met 3 hours a week. The sample reflects the current cultural and linguistic diversity of higher education in Spain with a high percentage of Erasmus students per class and the first students from an immigrant origin arriving at university.

The objective of the course was to develop not only fluency but also accuracy, quality and correctness in writing. Up to this point in their studies the students had mainly received instruction in the traditional face-to-face format. The students had never had the chance of using the language in authentic environments. In order to frame class blogs within an authentic context, students were provided with a list of 100 weblogs for library science where a world of information specific to their field of study is available and discussed. Following Farmer [17], the weblogs chosen allowed comments facilities and were able to attract vigorous debate i.e., weblogs which could be a medium to simulate effectively the successful formation of a community of inquiry

\section{B. Method}

Sixteen students were assigned to a control group receiving traditional lecture-discussion instruction, and sixteen students were assigned to an experimental group which was engaged in an active methodology, participating in blogs as professionals. To measure linguistic knowledge acquisition, a pre-test was administered to the students at the beginning of the semester, and an achievement test was conducted at the end of the semester as well as a questionnaire to get feedback on their motivation and their perceptions and attitudes towards the course.

Let us refer to the procedure followed by the students in the experimental group. This group attended introductory tutorials in which they were briefed on collaborative work, blog interaction and formal writing. Students worked in groups of four. The size of the group is important to reach maximum performance from each and every one of the students. In small groups there is better cohesion, intimacy, safety and trust [18]. The different groups of students got involved with their comments posted to some blogs of their choice. When doing so, they were mostly concerned with using the English language with accuracy. The teacher/facilitator played an important role in providing guidance to students to ensure their active and rich engagement in the activity. Students were required to share roles in the group: secretary-coordinator, facilitator, language expert and web expert so as to make sure that there be equal contribution. The profile of the language experts was carefully selected by the teacher not only on account of their higher command of the language but their capacity and willingness to assume the responsibility of solving linguistic problems of their peers and helping in their language development. The exchange of entries and the feedback received in the blogs were pasted in the university intranet forum, making them available to all the students participating in the experiment.

As for assessment, following [19], the teacher tracked the quantity of group posts and comments ( 80 posts were sent with an average of 70 words per post for a total of 5,600 words).We also considered the quality of writing and effort; grades were assigned accordingly. All the posts and comments were later analyzed in class for linguistic accuracy. The teacher also debriefed through in-class discussion encouraging participation reflecting on the content of the flow 
of messages exchanged, what they had learned through specific entries and the impact of the entry on its readers.

Debriefing was an opportunity to use the language communicatively, more than just a purely self-critiquing stage. The facilitator encouraged participation and ensured that all participants expressed what they wanted to. This stage was not regarded as a criticism of conduct and results, but as an opportunity for the students to use their language skills and comment on their work. Interpersonal problems, decisions taken, goals reached, language or communication errors made and content acquired were all set out and analyzed.

The portfolios showed that linguistic proficiency and students' creative expression were also rewarded. These portfolios, which incorporated the students' feedback on the experiment, were later handed in.

\section{RESULTS AND DISCUSSION}

The time spent in working on the blogs was quite long, not only writing, posting entries and replying to comments, but reading the loads of information contained in blogs as well. Nevertheless, the students reported high satisfaction on their participation. In class all the posts and replies were commented on and analyzed both from their linguistic point of view and from their information content, which frequently generated interesting in-class discussion. The experimental group critically assessed their own work and their classmates'.

Regarding our first hypothesis, if writing skills and fluency were more likely to show improvement by active participation in blogs than by using traditional teaching, results partly confirm it, as the analysis of our data do not differ much: the students in the experimental group obtained a slightly higher score than students in the control group (78.1\% vs. $71.9 \%)$ in post-test on language proficiency. Post-tests showed considerably more fluency in conveying ideas. The students wrote texts only a bit more carefully, but they reflected much more accuracy in the use of vocabulary to express their thoughts. The grammatical improvements basically involved the tense system, use of phrasal verbs and linking devices. The success of the activity may be based on the fact that students have been more exposed to the language which has contributed to make them more proficient.

As for our second hypotheses, i.e., if making the students get involved in blogs may have an increase in motivation, results largely confirm it. In the study, quantitative research included the measurement of students' course participation by recording class attendance, homework submission and participation in learning activities. On the other hand, to provide feedback from the learner's perspective, qualitative data on the students' background, attitudes, and motivation were collected from a questionnaire which was administered to the experimental group and the control group in the second class and the week before the final class of the semester. The questionnaire, completed by all the participants, was based on closed items. The experiment also included the teacher observation in the classrooms.

All students pertaining to the experimental and the control group were also individually interviewed throughout the semester to provide feedback from their perspective on their perceived interest, challenge, difficulty, and on their intrinsic motivation (enjoyment, sense of challenge, skill development) and extrinsic motivation (personal goals and aspirations) towards the course. The rationale for the interview questions was to gather information mainly relating to the blogging process and strategies, personal attitude towards the experience, and perceived language improvement. Data were organized, categorized, interpreted and synthesized following Creswell [20] and the subsequent analysis allowed the clustering of data into meaningful groups: the blogging process, personal attitude towards the experience, and language improvement.

Some students were further interviewed to clarify issues and to further validate data. The experimental group and the control group data were compared to observe motivation in both groups. The qualitative analysis of the results obtained from the questionnaires also confirmed the high motivation of the students engaged in active participation in blogs. The development of authentic communication of the students' field of studies, the expression of their own ideas in a foreign language and the participation in a social network based on their professional interests highly contributed to the success. Participants have shown a strong preference for blogging versus previous traditional writing. Writing for a purpose, doing it for an authentic audience and realizing that their opinions arrived at readers interested in the topic being discussed, has made them greatly motivated.

\section{CONCLUSIONS}

In order to maximize virtual performance in a professional setting, our results have confirmed the benefits of blogging in the language classroom mentioned by Arena [7]. The findings were positive since they contributed to the students' choice of more appropriate language, the addition of new perspectives to their thoughts, and the motivational aspect of realizing that one's voice is heard at a distance in an authentic situation, although simulated in part. Writing for a purpose, i.e., self-expression and self-reflection in blogs for professional development, has encouraged them to produce language more fluently. Students are also more concerned with correctness which leads us to consider blogs as a potential tool for the development of foreign language linguistic and communication skills. The activity aimed principally at improving writing skills in a virtual context; however, reading skills are likely to have also improved because of the intensive exposure to reading in the blogs, a fact which has promoted the relationship with a real audience beyond the instructor and for a real purpose.

This new learning environment and the meaningful context have raised high motivation in the students and will help them become life-long and more efficient learners. These results coincide with other studies on motivation and computer assisted language learning, which report that discussion initiated on the web motivates students more than teacher-initiated discussion. Students also produce more output and the learning results tend to be better (see for example [21]). Most students agreed on the fact that writing 
for a purpose had been very motivating and they valued the opportunity to develop writing skills in a real environment. Harris [22] reaffirms the idea that students are much more engaged in a learning activity that has value for them regardless of the amount of hard work when they believe that what they are learning meets their needs.

Simulation and gaming methodology in all its various dimensions fulfils these criteria: an amazing amount of work on the part of the participants and the facilitators, but ultimately meeting the needs of a "real-life" experience.

\section{REFERENCES}

[1] A. García-Carbonell, B. Rising, B. Montero, and F. Watts, "Simulation/gaming and the acquisition of communicative competence in another language," Simulation \& Gaming: An Interdisciplinary Journal of Theory, Practice and Research, vol. 36 , no. 4, 2001, pp. 481-491.

[2] R. Kern, "Restructuring classroom interaction with networked computers: Effects on quantity and characteristics of language production," The Modern Language Journal, vol. 79, 1995, pp. 457-476.

[3] M. Warschauer, "Computer-assisted language learning: An introduction," in S. Fotors, Ed., Multimedia Language Teaching, Tokyo: Logos International, 1996, pp. 3-20.

[4] S. Yardi, S. A. Golder, and M. J. Brzozowski, "Blogging at work and the corporate attention economy," in Proc. the SIGCHI Conference on Human Factors in Computing Systems, ACM, 2009, pp. 2071-2080.

[5] K. Pinkman, "Using blogs in the foreign language classroom," The JALT Call Journal, vol. 1, no. 1, 2005, pp. 12-24.

[6] C. Arena, "Blogging in the language classroom: It doesn't simply happen," TSEL-EJ. Teaching English as a Second or Foreign Language, vol. 1, no. 4, 2008.

[7] B. Montero-Fleta and C. Pérez-Sabater, "A research on blogging as a platform to enhance language skills," Procedia - Social and Behavioral Sciences, vol. 2, no. 2, pp. 773-777, 2010.

[8] J. Pellettieri, "Negotiation in cyberspace: The role of chatting in the development of grammatical competence," in M. Warschauer and R. Kern, Eds., Network-Based Language Teaching: Concepts and Practice, New York: Cambridge University Press, 2000, pp. 59-86.

[9] Y. Sun, "Voice blog: An exploratory study of language learning," Language Learning \& Technology, vol. 13, no. 2, pp. 88-103, 2009.

[10] L. Murray, T. Hourigan, and C. Jeanneau, "Blog writing integration for academic language learning purposes: Towards an assessment framework," Ibérica, vol. 14, pp. 9-32, 2007.

[11] E. Ushida, "The role of students' attitudes and motivation in second language learning in online language courses," CALICO Journal, vol. 23, no. 1, pp. 49-78, 2005.

[12] E. Ushioda, "Motivation and good language learners," in C. Griffiths (Ed.), Lessons from Good Language Learners, Cambridge: Cambridge University Press, 2008, pp. 19-34.

[13] R. Garris, R. Ahlers, and J. E. Driskell, "Games, motivation and learning: A research and practice model," Simulation \& Gaming: An Interdisciplinary Journal, vol. 33, no. 4, pp. 441-467, 2002.
[14] S. Choi and W. L. Johnson. (2005). Assessing Dynamic Aspects of Learner Motivation in Simulation/Gaming Based Foreign Language Learning Environment. [Online]. Available: http://www.informatics.sussex.ac.uk/users/gr20/aied05/finalVersion/ SChoi.pdf

[15] J. R. Williams and J. Jacobs, "Exploring the use of blogs as learning spaces in the higher education sector," Australasian Journal of Educational Technology, vol. 20, no. 2, pp. 232-247, 2004.

[16] N. Aharony, "Librarians and information scientists in the blogosphere: An exploratory analysis," Library \& Information Science Research, vol. 31, pp. 174-181, 2009.

[17] J. Farmer, "Communication dynamics: Discussion boards, weblogs and the development of communities of inquiry in online learning environments," in R. Atkinson, C. McBeath, D. Jonas-Dwyer, and R. Phillips, Eds., in Proc. the 21st ASCILITE Conference on Beyond the Comfort Zone, pp. 274-283, 2004.

[18] C. Pérez-Sabater and B. Montero-Fleta, "The study of Motivation in library and information management education: Qualitative and quantitative research," Journal of Information Technology Education: Innovations in Practice, vol. 11, pp. 213-226, 2012.

[19] A. Campbell, "Weblog applications for EFL/ESL: Classroom blogging, two fundamental approaches," TSEL-EJ. Teaching English as a Second or Foreign Language, vol. 9, no. 3, 2005.

[20] J. W. Creswell, Qualitative Inquiry and Research Design, Choosing Among Five Traditions, Thousand Oaks, CA, 1998.

[21] R. Harris. (1991). Some ideas for motivating students. [Online]. Available: http://www.virtualsalt.com/motivate.htm

[22] M. K. Jogan, A. H. Heredia, and G. M. Aguilera, "Cross-cultural e-mail: Providing cultural input for the advanced foreign language student," Foreign Language Annals, vol. 34, no. 4, pp. 341-346, 2001.

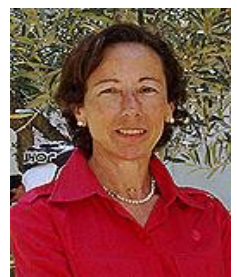

Begoña Montero-Fleta is a Ph.D. She is a senior lecturer at the Universitat Politècnica de València (Spain). Her areas of interests are the application of new technologies to language learning and the linguistic characteristics of scientific discourse and its assessment. As well as textbooks and material design for academic purposes, her publications and international conference presentations have addressed classroom innovations and new technologies applied to language teaching as well as comparative discourse.

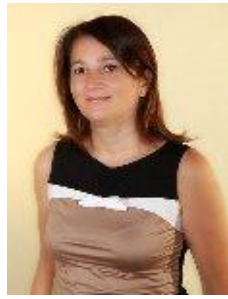

Carmen Pérez-Sabater is an associate professor. She has been lecturing in English for computer science at the Universitat Politècnica de València (Spain), the Department of Applied Linguistics, since 1990. She is currently working in the field of comparative discourse analysis, English for specific/academic purposes, computer-mediated communication and gender studies. Her research has been published in prestigious journals such as Ibérica, Journal of Pragmatics, Linguistik Online, RESLA, and Written Communication, among others. She has also coauthored several books on English for computer science and is an active member of academic institutions such as AELFE or the Informing Science Institute. 